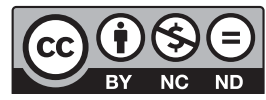

Estudos Teológicos foi licenciado com uma Licença Creative Commons Atribuição - NãoComercial - SemDerivados 3.0 Não Adaptada

http://dx.doi.org/10.22351/et.v59i1.3602

\title{
A CONSTRuÇão de PEQUENOS ESPAÇOS DE CUIDAdo E GRATUIDADE COMO RESISTÊNCIA ÀS VIOLÊNCIAS: UMA RELAÇÃO ENTRE PASTORAL E TEOLOGIA DA CIDADANIA ${ }^{1}$
}

\author{
The construction of little spaces of care and gratitude \\ as resistance to violence: a relation between \\ practical theology and the theology of citizenship
}

\begin{abstract}
Jefferson Zeferino ${ }^{2}$
Resumo: Por meio de um mapeamento das publicações sobre teologia pública no Brasil, nota-se que são recorrentes os textos que conjugam pastoral e teologia da cidadania. Essa relação é desenvolvida como modo de contribuição aos estudos em teologia pública, bem como tentativa de reflexão acerca do problema da violência. Ambienta essa discussão o contexto amplo de violências, o qual desmascara pretensas neutralidades e requer, do fazer teológico, uma aterrissagem atenta, histórica e sensível ao sofrimento humano. A partir da literatura marginal (Carrascoza) e da hermenêutica filosófica de Ricoeur, demonstra-se a contraposição entre cuidado e violência e se dialoga com a noção de pastoral como elemento que pode auxiliar a aprofundar a compreensão do cuidado como uma constante antropológica a ser refletida e cultivada enquanto elemento agregador na construção de pequenos espaços de cuidado e gratuidade.
\end{abstract}

Palavras-chave: Teologia Prática. Teologia pública. Teologia da cidadania. Cuidado pastoral. Violência.

Abstract: Through a mapping of the publications on public theology in Brazil, it's notable that texts that conjugate practical theology and the theology of citizenship are numerous. This connection is developed as a contribution to the studies in public theology, as well as an attempt to reflect on the matter of violence. The context of violence grounds the discussion unmasking pretense neutralities, requiring a cautious, sensible and historical theological labor regarding human suffering. Based on marginal literature (Carrascoza) and on Ricoeur's philosophical hermeneutics, the text shows the tension between care and violence, as well as it dialogues with the notion of pastoral as

1 O artigo foi recebido em 24 de fevereiro de 2019 e aprovado em 27 de abril de 2019 com base nas avaliações dos pareceristas ad hoc. A pesquisa contou com apoio da CAPES.

2 Doutor em Teologia pela Pontifícia Universidade Católica do Paraná (PUCPR), onde também desenvolve seu estágio pós-doutoral. Professor e coordenador do bacharelado em Teologia da Faculdade São Braz em Curitiba/PR. Contato: jefferson.zeferino@hotmail.com 
an element that may help to deepen the comprehension of care as an anthropological constant to be reflected and becomes an aggregating term for the construction of little spaces of care and gratitude.

Keywords: Practical Theology. Public Theology. Theology of Citizenship. Pastoral Care. Violence.

\section{Considerações iniciais}

A presente abordagem se desenvolve por meio do que entendemos ser uma teologia pública. Cabe salientar que o público é assumido aqui em duas dimensões: 1. As questões do espaço público como temas teológicos (cuidado e violência, p. ex.). 2. O discurso teológico atento a critérios públicos de argumentação no contexto acadêmico. Deste modo, o público é tanto assunto da teologia como critério de sua linguagem. A presente análise reflete acerca do espanto (thaumazein) causado pela violência. Com efeito, violência e sofrimento são elementos compreendidos enquanto constantes antropológicas das mais emergenciais. Trata-se daquilo que Luiz Carlos Susin denomina do mais humano ${ }^{3}$. Isto é, diante das comonalidades ${ }^{4}$ observáveis na experiência humana, a dor e o sofrimento constituem certa precedência. A violência, outra constante antropológica, é compreendida como causa recorrente de sofrimento. A ela contrapõe-se outro elemento constitutivo da vida humana, a saber, o cuidado. Desenvolve-se, portanto, a relação dialética entre violência e cuidado. Para tanto, elabora-se um roteiro com quatro estações: 1 . Sobe-se o morro para que se observe a relação gentil entre um filho e uma mãe que são traspassados pela violência. 2. Ouve-se atentamente uma alocução de Paul Ricoeur no contexto do memorial da Shoah, em que conjuga louvor e lamentação. 3. Reflete-se acerca da pastoral em sua relação com o espaço público com um olhar atento para o tema do cuidado. 4. Por fim, à guisa de conclusão, estabelecem-se relações entre as estações anteriores apontando para uma teologia pública com enfoque no cuidado enquanto denúncia das violências.

3 Aqui nos baseamos em palestra ministrada por Luiz Carlos Susin no âmbito do Congresso Humanitas da PUCPR em 2018. Esse olhar pelos mais vulneráveis, contudo, é presente em toda a teologia da libertação. Corrobora a noção de mais humano, a conversão do olhar evocada por Susin enquanto conversão à realidade concreta da vida humana. Trata-se, com efeito, da perspectiva a partir de baixo. Ver: SUSIN, L. Conversão ecológica: "conversão da conversão". In: MURAD, A.; TAVARES, S. (Orgs.). Cuidar da casa comum: chaves de leitura teológicas e pastorais da Laudato Si'. São Paulo: Paulinas, 2016. p. 40-51.

4 Terminologia utilizada por teólogos sul-africanos, aponta para aspectos comuns na experiência humana que podem servir de ponto de contato para o desenvolvimento de uma teologia pública. Neste contexto, o público está relacionado ao que é comum (GRUCHY, J. Public Theology as Christian Witness: exploring the genre. International Journal of Public Theology, v. 1, p. 26-41, 2007; GRUCHY, S. Of agency, assets and appreciation: seeking some commonalities between theology and development. Journal of Theology for Southern Africa, v. 117, p. 20-39, nov. 2003). 


\section{Uma imagem que alarga horizontes: no morro}

O método da teologia da libertação ver-julgar-agir, em especial desde a sistematização clodovisiana ${ }^{5}$, compreende seu primeiro passo como uma abordagem da realidade enriquecida pelos dispositivos de análise das ciências sociais. Assim como o próprio Clodovis Boff reconhece no prefácio autocrítico da segunda edição de seu texto, outras mediações poderiam ser melhor desenvolvidas junto às ciências do social. No presente momento, opta-se pelo acesso à realidade por meio da literatura marginal. Essa, por sua vez, atua como alargadora de horizontes, bem como sensibilizadora para a realidade de sofrimento e violência vivida por muitas pessoas, em especial aquelas que vivem em situação de pobreza. Deste modo, o texto No morro de João Anzanello Carrascoza ${ }^{6}$ é apresentado aqui por meio de parágrafos selecionados dispostos em sequência. Pede-se uma licença aos leitores e às leitoras para que compreendam a utilização de citações longas consecutivas, pois apresentam de modo sumário esse conto, bem como privilegiam a bela tessitura que Carrascoza costura com sua poesia. Espera-se que este espaço de discussão acadêmica também esteja atento à função estética da leitura, mesmo quando se trata de uma literatura científica. $\mathrm{O}$ autor narra o amor entre um filho e uma mãe no morro (favela), ilustrando uma relação gentil e carinhosa (sagrada) entre eles.

Gostava de vê-la, mãe, vivendo silenciosamente a sua vida diante dele, sem gritos e resmungos, assim como ele à frente dela. E tanta era a força de seu olhar que a mulher sentiu como se lhe ardesse uma brasa na nuca e virou-se, desconfiada de que os anos a tivessem iludido e, ao girar, de repente, encontrasse não seu menino, e sim um homem, quase a bater a cabeça no teto, o homem que ele seria um dia, não a criança que agora era - e, imperceptivelmente, a usina de seu corpo o gerava. ${ }^{7}$

A mãe o examinou como quem descasca uma cebola, tirando as películas que escondem o seu miolo sadio e, se o filho se enternecia vendo-a pelas costas - esperando que se virasse e lhe revelasse um sorriso de cumplicidade -, a mãe podia detectar o que ainda era semente nele, o que raiz, e reconhecê-lo pelo avesso, folha que se soltara de seu corpo, como a pena caída ainda o é do pássaro. ${ }^{8}$

Bom, quando tinha a idade do filho, não sabia que haveria de passar a vida a fazer tantas coisas às pressas, e todas a dar em nada, que nada era aquele viver, só suportável por ter os olhos dele envolvendo-a em silêncio - grãos únicos de luz na nuvem de poeira que era. ${ }^{9}$

O menino saíra para desenhar no lado de fora.

\footnotetext{
BOFF, C. Teologia e prática: Teologia do Político e suas mediações. Petrópolis: Vozes, 1993.

6 CARRASCOZA, J. No morro. In: ANACOANA, P. (Org.). Eu sou favela. São Paulo: Nós, 2015. p. 9-18.

CARRASCOZA, 2015, p. 11-12.

CARRASCOZA, 2015, p. 12.

CARRASCOZA, 2015, p. 13.
} 
O calor atordoava, mas o vento circulava pelas ruas do beco e vinha dar naquela ruela onde ele colhia mais uma tarde de sua vida. E era vento tão vigoroso, que entrou sem cerimônia no barraco, derrubou umas ripas de madeira e chegou até a mãe diante do fogão. Ela sentiu com gratidão aquele frescor e girou o corpo como se pudesse ver o vento, como se ele fosse um conhecido que ali chegasse para saudá-la, mas se não o viu, invisível que era, o visível agarrou-se aos seus olhos como um imã: emoldurado pelo retângulo da porta, estava seu menino, de costas, a cabeça baixa, a nuca semicoberta pelos cabelos, as espáduas magras, os cotovelos dobrados, a bermuda abaixo da cintura, revelando o rego das nádegas. Comoveu-se ao vê-lo daquele ângulo, que realçava ainda mais a sua fragilidade. A ele não tinha nada a oferecer senão a sua muda resignação, a comida que nem sempre conseguia comprar com os caraminguás das esmolas, a vida sem esperança. Às vezes, em desespero, tinha desejos de se atirar à frente dos ônibus que passavam velozes na avenida beira-mar, mas um fiapo de sonho a impedia, e lá estava ele, inconsciente de sua força, sem saber que, à semelhança de um prendedor no varal, segurava a existência dela como uma roupa seca. ${ }^{10}$

De súbito, uns rapazes passaram correndo pelo beco em fuga; o menino sequer pode ver quem eram, e já no encalço lhes seguiam uns policiais armados, aos gritos. [...] O menino ouviu outros estampidos. E, antes que os policiais sumissem morro acima, sentiu algo lhe beliscar o peito. [...] Um vulto se inclinou sobre ele, não conseguia distinguir seu rosto, mas sabia: era a mãe. E ela o abraçava com força, podia sentir suas costelas magras e sua boca de café. ${ }^{11}$

Começou a tremer. Tentou dizer à mãe que sentia frio, mas não lhe saíam palavras. Parecia que ela o embalava no colo e o levava para dormir no colchão. Onde estava a bola? Queria pegá-la, mas faltava-lhe força. Abriu a mão, o lápis de cor caiu na terra. Ouviu outro estampido, remoto. Depois, o zunir do vento, desfolhando as páginas brancas de seu caderno, tingidas do mais vivo vermelho. ${ }^{12}$

THAUMAZEIN! Pode-se imaginar que o espanto atravessa a pessoa que lê como um tiro, revelando-lhe aquilo que lhe há de mais humano. A relação entre as humanidades do texto e do leitor e da leitora se encontram em uma relação dialógica que não se contenta com a realidade, traz à tona a memória do sofrimento.

\section{Uma interpelação filosófica: a memória do sofrimento}

Arrisca-se aqui uma conversa com Paul Ricoeur, conscientes de que o que se tenta é uma tradução dialógica de sua dialética para dentro da discussão ensejada. Sob o impacto do conto sobre o menino e sua mãe, dá-se mais um passo na direção da reflexão sobre a dor.

Em 1989, no dia da memória do Holocausto (Yom Ha-Shoah), Paul Ricoeur foi convidado pelo rabino Joseph A. Edelheit a fazer uma fala durante uma celebração

\footnotetext{
${ }^{10}$ CARRASCOZA, 2015, p. 14-15.

${ }^{11}$ CARRASCOZA, 2015, p. 17.

12 CARRASCOZA, 2015, p. 18.
} 
interconfessional na cidade de Chicago. Em sua alocução, Ricoeur diz que aquele momento era um memorial que apontava para a necessidade do não esquecimento. Lembra também que é comum na Bíblia a memória da Lei de Moisés como um dom. Nesse horizonte, a memória está relacionada com a libertação (da casa da escravidão no Egito). Diante disso, contrapõe as duas memórias: libertação e holocausto. ${ }^{13}$

Ambas memórias são necessárias. O autor afirma: “[...] devemos lembrar-nos porque lembrar-se é um dever moral. Temos uma dívida em relação às vítimas. $\mathrm{E}$ a forma mínima de pagar nossa dívida é dizer e redizer o que se passou em Auschwitz" (ou no morro). "Vamos além: rememorando e dizendo, não só evitamos que o esquecimento mate as vítimas uma segunda vez; evitamos que a história de suas vidas se torne banal". Com isso, a memória estabelece uma dupla função, trazer à luz o ocorrido, bem como evitar o esquecimento por meio da banalização. "A tarefa da memória consiste em preservar a dimensão escandalosa do acontecimento, a manter o que é monstruoso como inesgotável pela explicação". A normalização da violência ou sua explicação teológica (teodiceia) tendem a mascarar a crueza dos fatos, buscando esconder as terríveis faces dos algozes. "Graças à memória e às narrativas que preservam essa memória, a unicidade do horrível - unicidade única, se ouso dizer assim - é preservada de um nivelamento pela explicação."14

Ricoeur contrapõe-se, portanto, às explicações que atenuam as violências, inclusive por meio da responsabilização das vítimas. "Além das explicações que nivelam e banalizam o acontecimento criminoso ao qual está dedicado este memorial, há explicações que justificam e fazem aparecer os sofrimentos das vítimas como se fossem merecidas". Aspecto que Ricoeur identifica com uma teologia da retribuição que possui base, bem como contraponto no interior dos textos bíblicos. ${ }^{15}$

Contra a teoria da retribuição, na qual uma vítima mereceria a violência, emerge a percepção de que "[...] quando a queixa das vítimas inocentes não é mais coberta por argumentos de justificação, essa queixa nua é levada ao estado de puro grito". Assim, "enquanto a teoria da retribuição torna igualmente culpáveis vítimas e algozes, a lamentação revela os algozes como algozes e as vítimas como vítimas". Não há escapatória - o grito pode ser visibilizado. "Assim podemos fazer memória das vítimas pelo que elas são: a saber, os portadores de uma lamentação que nenhuma explicação é capaz de abrandar". É nesse horizonte que Ricoeur relembra a dialética entre louvor e lamento. "Uma vez mais, o movimento de ida e volta, da lamentação ao louvor, do louvor à lamentação - essa alternância dramática subentendida no livro dos salmos - é reativada." ${ }^{\prime \prime 6}$

Louvor e lamento se reencontram, trata-se da memória da libertação (louvor) e da memória do Holocausto (lamento). "A lamentação tem necessidade de memória tanto como o louvor". Assim, "lembrar-nos-emos dos seis milhões, com tanto mais devo-

\footnotetext{
13 RICOEUR, P. A memória do sofrimento. In: RICOEUR, P. A hermenêutica bíblica. São Paulo: Loyola, 2006. p. 239-240.

14 RICOEUR, 2006, p. 240-241.

15 RICOEUR, 2006, p. 241.

16 RICOEUR, 2006, p. 242.
} 
ção se reconhecermos que Deus, de cuja bênção nós recordamos por ocasião da Páscoa, não é a causa do sofrimento, mas antes o autor da Torah que diz 'Não matarás'.’17

A memória atua na mediação entre sofrimento e louvor, entre violência e graça. A memória emerge como mecanismo de reação às violências estruturais que buscam promover esquecimentos programáticos em virtude de uma coesão narrativa, quiçá a título de uma pretensa neutralidade. A memória representa a ruptura com o estabelecimento da violência, seja ela qual for. A memória ativa a dor e o alívio, o lamento e o louvor, o sofrimento e a graça, a violência e o cuidado. Trata-se do primeiro movimento de resistência.

\section{Uma correlação teológica: o cuidado pastoral}

Diante do impacto da narrativa do morro e a partir da chave de leitura emprestada de Ricoeur, nota-se a pertinência da contraposição entre cuidado e violência. O conto sensibiliza para a necessidade da memória do sofrimento. Cabe, neste momento, um recorrido teológico que ajude a identificar de modo mais atento elementos referentes ao cuidado. Neste contexto, é válido notar que a própria ideia evocada pelo termo pastoral já é uma metáfora. Assim como um pastor apascenta suas ovelhas, também um obreiro (a)/ministro(a)/sacerdote cuidará das pessoas de sua comunidade.

Por meio de um mapeamento das publicações sobre teologia pública no período entre 2000 e 2017, notam-se temas ligados à Teologia Prática como recorrentes. ${ }^{18}$ Por meio dessa catalogação, as seguintes palavras-chave foram identificadas: culto cristão/liturgia; diaconia; homilética; missão; pastoral; Teologia Prática. Dentre esses, destaca-se a palavra-chave pastoral. Por sua vez, das abordagens sobre pastoral no contexto de uma teologia pública se evidenciam as abordagens que conjugam pastoral e cidadania. Deste modo, atenta-se agora para as contribuições de Clóvis Pinto de Castro, Evaldo Luís Pauly, Alonso Gonçalves e Natanael Gabriel da Silva.

\section{Uma pastoral da cidadania}

O teólogo metodista Clóvis Pinto de Castro desenvolve o que chama de uma pastoral da cidadania. Parece elementar destacar que Castro se preocupa com a dimensão pública da fé conectada à perspectiva do cuidado pastoral. Sua proposta está pautada, sobretudo, em quatro elementos:

1. Dimensão pública da teologia cristã. A teologia da cidadania de Castro encontra bases nas teologias da práxis do século XX (Moltmann, Metz, Cox). Percebe um movimento de desprivatização da fé nessas teologias políticas, bem como a noção de reserva escatológica, que reflete o confronto entre realidade histórica e o horizonte

17 RICOEUR, 2006, p. 243.

18 ZEFERINO, J. Karl Barth e teologia pública: contribuições ao discurso teológico público na relação entre clássicos teológicos e res publica no horizonte da teologia da cidadania. 2018. Tese (Doutorado) - PPGT/ PUCPR, Curitiba, 2018. p. 28-29. 
utópico das promessas escatológicas, especialmente as perspectivas de um shalom e de um reino de Deus. ${ }^{19}$

2. Justiça e direito. A discussão sobre uma pastoral possui um contexto definido em regimes democráticos - a cidadania. Nessa direção, compreende uma atuação cidadã, na luta por um país melhor em que todos e todas possuam seus direitos fundamentais respeitados diante de um quadro de bem-estar social, o que é identificado com um shalom. Esse conceito é correlacionado com a plenitude da justiça, bem como a perspectiva da paz enquanto bem-estar abrangente. Desse modo, o shalom é também um serviço (diaconia) de construção de novos lugares de shalom, onde se experimente justiça e paz. ${ }^{20}$

3. Boas obras. Com a ideia de justiça veterotestamentária identifica-se a noção neotestamentária de boas obras. Trata-se aqui da perspectiva de uma fé em ação. A prática da justiça (boas obras) seria a base ética do reino de Deus. Por sua vez, as boas obras estão fundamentadas no amor ao próximo e na graça de Deus. Essa atuação não está restrita ao ambiente eclesial, mas é pública. Ética e espiritualidade estão unidas num único movimento de amor ao próximo por meio das boas obras e da prática da justiça. $^{21}$

4. Shalom. O termo shalom é de difícil tradução. Mas está ligado a noções de bem-estar, justiça, comunhão, harmonia, prosperidade, vida em plenitude. Trata-se do conteúdo do reino de Deus. Com isso pensa-se num horizonte ativo, construído por meio da prática da justiça e das boas obras. Desenvolve-se assim a perspectiva da cidadania como modo de aproximação da perspectiva teológica do reino de Deus e enquanto meio para a construção de uma sociedade mais justa no horizonte do bem comum. $^{22}$

Estabelecida a base bíblica de sua teologia da cidadania, o autor as relaciona com a noção de pastoral. Para ele, a pastoral é uma ação pensada e sistematizada, realizada pelo povo de Deus a serviço do bem comum, movida pelo horizonte utópico do reino de Deus e encarnada na realidade concreta do cotidiano. ${ }^{23}$

É nesse horizonte que o autor desenvolve sua proposta de uma fé cidadã. Essa perspectiva contrapõe-se a uma vida comunitária voltada exclusivamente para si mesma. Com isso, a desprivatização da fé é lida nesse movimento em saída, uma vez que é a própria fé que motiva essa dinâmica de envolvimento no espaço público. O cuidado, portanto, é vivenciado para dentro e para fora da comunidade de fé. ${ }^{24}$

A ação pastoral inclui ainda uma educação para a cidadania. Efetivamente, pensa-se numa educação para o cuidado, relacionada aqui, de modo especial, com o espaço público. Deste modo, elabora-se uma pedagogia da cidadania na direção do fortaleci-

19 CASTRO, C. Por uma fé cidadã: a dimensão pública da igreja. Fundamentos para uma pastoral da cidadania. São Paulo: Loyola; São Bernardo do Campo: Universidade Metodista de São Paulo, 2000. p. 84-86.

${ }^{20}$ CASTRO, 2000, p. 87-88.

${ }^{21}$ CASTRO, 2000, p. 88-96.

${ }^{22}$ CASTRO, 2000, p. 96-101.

${ }^{23}$ CASTRO, 2000, p. 105.

${ }^{24}$ CASTRO, 2000, p. 109-111. 
mento da democracia, da criação de uma cultura de zelo, carinho e dedicação pela res publica, por meio de iniciativas de sensibilização e conscientização. ${ }^{25}$ Esse trabalho educativo, portanto, é realizado por meio do envolvimento na vida da sociedade. ${ }^{26}$

A educação para a cidadania, portanto, ocupa espaço privilegiado nessa proposta de pastoral, apontando, mediada pela noção do shalom, para "[...] a (re)construção de cidades mais justas, solidárias, onde não haja seres sobrantes, onde todos possam viver em condições mínimas de bem-estar-social (espaço público do shalom) [...]”27.

\section{Pastoral urbana e cidadania}

O teólogo e educador de tradição luterana Evaldo Luis Pauly, em texto de $1994^{28}$, relaciona pastoral e espaço urbano. Nesse contexto, "mesmo que a pastoral precise trabalhar com verdades eternas, mensagens divinas, dogmas de fé e rituais milenares, ela não pode transferir para si mesma a infalibilidade de um pretenso domínio absoluto dessas verdades, mensagens e dogmas". Ademais, "pelo que a realidade indica, a pastoral não tem a mínima capacidade de vencer o desafio urbano. [...] Apenas a sociedade democrática, com sua cidadania organizada e atuante, tem condições de enfrentar o desafio urbano com relativa possiblidade de êxito". Assim, "se a pastoral deseja enfrentar a realidade, deve aliar-se a essa cidadania democrática organizada, deve submeter-se à sociedade civil". Esse quadro "[...] requer da Igreja mais capacitação leiga do que teológica". Isto é, "ou laiciza-se a pastoral, democratizando-a, ou não haverá pastoral urbana capaz de enfrentar o multifacético problema urbano"29. Mais, diante do debate sobre tecnologias urbanas, entende-se que "sem os leigos e seus saberes, a pastoral urbana é uma inviabilidade" ${ }^{30}$.

A partir do olhar da psicanálise, Pauly indica que "[...] a pastoral precisa reconhecer o caráter doentio de determinadas expressões religiosas". Para o autor, "a fé evangélica incentiva a crítica da religião, e a crítica da religião, por sua vez, permite aprimorar e consolidar uma fé mais livre e libertadora" ${ }^{31}$. Com isso, emerge o desafio da escuta. Na relação entre psicanálise e pastoral, ambas objetivando a felicidade das pessoas, concebe-se uma pastoral que precisa ouvir. "Na cidade, a Igreja que não sabe ouvir não tem o que dizer." ${ }^{\prime 2}$

${ }^{25}$ CASTRO, 2000, p. 114-118.

${ }^{26}$ CASTRO, 2000, p. 124-125.

${ }^{27}$ CASTRO, 2000, p. 119.

${ }^{28}$ O texto de Pauly é registrado na presente pesquisa, pois é acionado por Rudolf von Sinner (2012) no desenvolvimento de sua teologia da cidadania. Entretanto, do mesmo modo que Carlos Caldas identifica a obra de Castro, também o trabalho de Pauly pode ser compreendido como um caso de teologia pública avant la lettre. Ver: CALDAS, C. Dietrich Bonhoeffer e a teologia pública no Brasil: o conceito bonhoefferiano de 'estar aí para os outros' como pressuposto teórico para a construção de uma teologia pública no Brasil. São Paulo: Garimpo, 2016. p. 54-55.

${ }^{29}$ PAULY, L. Cidadania e pastoral urbana. São Leopoldo: Sinodal, 1994. p. 46-47.

${ }^{30}$ PAULY, 1994, p. 129.

${ }^{31}$ PAULY, 1994, p. 73.

32 PAULY, 1994, p. 169. 
Diante do novo texto constitucional, Pauly fala da submissão à autoridade desse documento, bem como sua promoção. "Neste sentido a pastoral tem um caráter conservador: conservando a tradição de obediência à autoridade e, dialeticamente, um caráter revolucionário: utilizando todos os meios ao seu alcance para difundir a prática cívica da participação popular na gestão da coisa pública.” Trata-se, portanto, apesar dos limites da Constituição Federal, de obedecê-la, promovê-la e revisá-la na prática da democracia. ${ }^{33}$

O texto de Pauly, do início da década de 1990, celebra a Constituição Federal e o fim do período do regime ditatorial. "Atualmente essa pastoral desenvolve sua prática num contexto em que predomina a cidadania pela metade; assim, essa pastoral acaba se transformando num movimento político em busca da inteireza da cidadania." ${ }^{34}$ Atualmente, a noção de cidadania pela metade pode ser novamente evocada. Na medida em que pessoas são privadas de seus direitos - educação, saúde, segurança, vive-se um quadro generalizado de cidadania pela metade ou, na expressão de Jessé Souza, de subcidadania ${ }^{35}$.

Com efeito, a originalidade da abordagem de Pauly, como ele mesmo estabelece, é a observação daquilo que a sociedade espera da pastoral. Para tal análise mune-se da Constituição Federal (CF), que fala sobre visitas a pessoas doentes em hospitais, liberdade de culto, casamento, organização institucional das igrejas. Com isso, o autor conclui que "a CF mais secularizada que o país já teve quer a pastoral atuando na sociedade!"36. Essa chave de leitura pode nos relembrar também um dos tópicos que o teólogo sul-africano Clint Le Bruyns aponta como necessário para a pertinência teológica na atualidade, o escrutínio popular. ${ }^{37}$ Isto é, ouvir do povo o julgamento sobre as ações teológicas, eclesiais, pastorais. A presente abordagem, por sua vez, parte da suspeita de que, mesmo que não queiram ter nada a ver com a religião, as pessoas gostariam de cuidado. Esse serviço, em sua gratuidade, pode ser real contribuição da pastoral para a vida da sociedade.

Em suma, Pauly propõe uma pastoral urbana [1] consciente do chão onde pisa, daí sua atenção à democracia e à constituição bastante recente quando da formulação de suas pesquisas; [2] atenta à prática da cidadania como modo de tentativa de superação da cidadania pela metade; [3] ciente de que as pessoas são seres com medos, anseios, desejo de felicidade, enfim, de subjetividades complexas; [4] plural, laicizada, assessorada pelos saberes vários de leigos e leigas; [5] apaixonada, sensível à realidade das pessoas, e a partir daí capaz de construir racionalidades adequadas e pertinentes.

${ }_{33}$ PAULY, 1994, p. 98-99.

${ }^{34}$ PAULY, 1994, p. 167.

${ }^{35}$ SOUZA, J. Subcidadania brasileira: para entender o país além do jeitinho brasileiro. Rio de Janeiro: LeYa, 2018.

${ }^{36}$ PAULY, 1994, p. 171.

${ }^{37}$ LE BRUYNS, C. O renascimento da teologia do kairos e suas implicações para a teologia pública e a cidadania na África do Sul. In: BUTELLI, F.; LE BRUYNS, C.; SINNER, R. Teologia pública no Brasil e na África do Sul: cidadania, interculturalidade e HIV/Aids. São Leopoldo: Sinodal; EST, 2014. p. 62. 
Outro autor que se dedica ao tema da pastoral no horizonte da cidadania é o teólogo batista Alonso Gonçalves. Ao falar sobre o desenvolvimento de uma teologia pública no contexto brasileiro, destaca a relevância que a cidadania tem ocupado no debate. ${ }^{38}$ Contudo, apresenta a seguinte ressalva: "A reflexão em torno da cidadania é de suma importância, mas ela procura olhar o público apenas pela perspectiva de fora”. Diante disso, propõe "[...] uma pastoral pública porque esta pode ser um instrumento da igreja em ações integrais da igreja com a coisa pública, procurando participar da vida citadina e seus dilemas como saúde, política e felicidade" ${ }^{\prime 39}$. Sua proposta de pastoral pública, portanto, é pensada como uma via ativa da teologia ocupada com as questões do espaço público, o que reverbera significativamente o intento de Castro. Para Gonçalves, cabe a essa pastoral perceber o dinamismo do cenário público, bem como "[...] a religiosidade, ou espiritualidade, sem comprometimento ou engajamento social ou de natureza cidadã por parte de seus integrantes [...]". O que justificaria a necessidade de uma teologia pública, dentro da qual "[...] uma Pastoral Pública seja um caminho a percorrer, ou seja, um caminho que chame a igreja a assumir a sua condição de organizadora de sentido na sociedade a fim de contribuir e se fazer sentir com credibilidade e respeitabilidade tanto em seu discurso público quanto em sua práxis". Isto é, pensa-se numa "[...] pastoral pública [que] abarcaria tanto o lado político do agir da comunidade de fé quanto à revitalização de uma espiritualidade com engajamento social" ${ }^{\prime \prime}$. Com isso, Gonçalves percebe o crescente fluxo de pessoas que buscam ou desenvolvem algum tipo de espiritualidade, sem estar ligadas a alguma instituição religiosa. Desta forma, "[...] a ação da igreja (que por si só já é pública) na esfera pública [...]", teria como locus a cidade em suas dinâmicas sociais e religiosas. $\mathrm{O}$ autor propõe " $[\ldots]$ uma pastoral de solidariedade independentemente de credo ou confissão - daí a necessidade ecumênica de engajamento entre as confissões; uma pastoral de integração da pessoa e seu ambiente vivencial"41.

Em publicação posterior, em coautoria com Natanael Gabriel da Silva, Gonçalves continua seu desenvolvimento no horizonte da pastoral, agora, porém, ao invés do termo pastoral pública, utilizam pastoral urbana. Os autores apontam que "uma pastoral urbana parece não poder ser problematizada de forma mais adequada, senão pelo caminho de uma teologia pública, num encontro entre teologia e cidadania"42. Apresentam a atuação pública/urbana da pastoral a partir de três pontos: 1. "movimentos associativos: o ajuntamento da comunidade para resolver problemas comuns como infraestrutura, segurança, melhorias no bairro"; 2. "trabalho voluntário: quando

${ }^{38}$ GONÇALVES, A. Pastoral Pública: a possibilidade de uma práxis a partir da Teologia Pública. Protestantismo em Revista, São Leopoldo, v. 27, n. 1, p. 25-35, jan./abr. 2012. p. 32.

${ }^{39}$ GONÇALVES, 2012, p. 35.

${ }^{40}$ GONÇALVES, 2012, p. 33.

${ }^{41}$ GONÇALVES, 2012, p. 34.

${ }^{42}$ GONÇALVES, A.; SILVA, N. Pastoreio e compaixão: uma contribuição à pastoral urbana a partir da teologia pública. São Paulo: Fonte, 2013. p. 85 
a comunidade se envolve com os problemas do outro se doando por algumas horas"; 3. "o agir político: com um consenso de igualdade e fraternidade buscar pontos em comum para uma melhor qualidade de vida". Destacam ainda que "a práxis se dá nos bairros como oportunidades de ação, sendo a comunidade solidária e tendo mais participação nos problemas do bairro, como tráfico de drogas, delinquência infantil". A participação nos bairros, portanto, poderia fazer com que as pessoas se comprometam de tal forma com as situações locais que se envolvam na "[...] criação de entidades para uma ação social diante das escolas, presídios, hospitais; nas empresas e sindicatos, buscando melhorar as condições dos trabalhadores". Além de um engajamento “[...] mais firme e comprometido por meio dos cidadãos na política, procurando levar propostas ao Poder Público do que pode ser melhorado na cidade ou no bairro". Por fim, os autores identificam essa pastoral com a evangelização que acontece por meio da atuação concreta de comunidades cristãs na vida da cidade e do bairro. ${ }^{43}$

Em resumo, com base em autores como Libânio, Comblin e von Sinner, desenvolvem sua proposta de pastoral urbana:

A pastoral urbana - a ação da igreja (que por si só já é pública) na esfera pública - teria um olhar para a realidade social e religiosa da cidade; uma pastoral de solidariedade independentemente de credo ou confissão - daí a necessidade ecumênica de engajamento entre as confissões; uma pastoral de integração da pessoa e seu ambiente vivencial ${ }^{44}$.

Efetivamente, a proposta de integrar a cidadania na perspectiva de pastoral demonstra-se em interlocução pertinente à teologia da cidadania como teologia pública e enquanto possível continuidade ao programa teológico de Castro.

\section{À guisa de conclusão: uma conversa sobre violências, cuidado e a construção de pequenos espaços}

A narrativa sobre a mãe e seu menino, apesar de ser um conto ficcional, nos remete à uma realidade de violência. Traz à memória o sofrimento de tantas outras famílias que estão passando, já passaram ou ainda passarão por esse tipo de dor. Cabe, neste contexto, sempre lembrar a sábia colocação de Bonhoeffer: "A Bíblia direciona o ser humano à impotência e ao sofrimento de Deus; apenas um Deus sofredor pode ajudar" ${ }^{45}$. Ou ainda a indicação de uma pastoral leiga, elaborada por Pauly, "[...] que se vincule às pessoas necessitadas de um Deus que seja amparo dos fracos"46. Diante

43 GONÇALVES; SILVA, 2013, p. 95.

${ }^{44}$ GONÇALVES; SILVA, 2013, p. 100. A mesma formulação é encontrada no texto anteriormente apresentado de GONÇALVES (2012, p. 34), substituindo-se o termo "urbana" por "pública". Como os autores não se ocupam com a explicação da alteração de pastoral pública para pastoral urbana, é possível uni-las na ideia de pastoral público-urbana.

45 "The Bible directs man to God's powerlessness and suffering; only the suffering God can help". BONHOEFFER, D. Letters and Papers from Prison. Editado por E. Bethge. London: SCM, 2017. p. 134.

46 PAULY, 1994, p. 130. 
do mais humano - dor e sofrimento -, a imagem de um deus triunfalista, que opera em lógica retributiva, não pode salvar. Apenas a sensibilidade de quem também sofre é consoladora. Neste horizonte, a memória que ativa a sensibilidade possui potencial salvifico, pois opera uma presença em cuidado. Com isso, cabe atentar à dialética ricoeuriana entre lamento e louvor para reler a história para além da violência, em busca do cuidado e, com isso, redescobrir a graça.

Voltando ao conto, observa-se que há um profundo cuidado entre o menino e a mãe. No início do conto o menino volta ofegante para casa depois de ter ido à venda, trazendo algo para sua mãe que preparava uma comida. Há um auxílio mútuo, um cuidado relacional. Carrascoza toma o cuidado de retratar o carinho que havia entre eles, a ternura da observação do outro. Enxergavam um ao outro e isso lhes dava sentido. A graciosa curiosidade com a qual o menino lia seu mundo (em meio à pobreza), bem como o gracioso labor de sua mãe na luta por algo que lhes sustentasse, ao mesmo tempo, anunciam o amor revolucionário de suas relações e denunciam um contexto de desigualdade e violência estrutural. Já viviam, portanto, entre o cuidado e a violência. Por fim, a violência derradeira os priva de si mesmos, do cuidado recíproco, da salvação relacional que desfrutavam.

A crueza do sofrimento humano grita como aquele urgente urgentíssimo, para se utilizar uma expressão do pensamento de libertação, que não pode ser olvidado. Diante disso, pensa-se, desde a tradição cristã, na imagem da pastoral como a perspectiva de um cuidado com a vida efetivada de modo gratuito. Isto é, a partir de uma ética de gratuidade compreende-se a possibilidade do cuidado no espaço público. Trata-se de uma forma de revolta contra as estruturas desumanizantes que condenam seres humanos a violências várias.

O cuidado, conteúdo da pastoral, pode ser aplicado também em sua dinâmica de zelo profético. Cuidar da memória, como recomenda Ricoeur, configura-se em elemento estruturante de uma teologia pública. Os judeus rememoram a Shoah, as mães da Plaza de Mayo relembram seus filhos e filhas, as manifestações do grito dos excluídos trazem à luz realidades de opressão, a Comissão Nacional da Verdade fala em memórias reveladas, a literatura marginal rememora a existência às margens. Desde a indicação de Ricoeur, percebe-se que a memória da violência, sem justificação dos algozes por meio da culpabilização das vítimas, desmascara pretensas neutralidades. Em virtude disso, “[...] não é possível o discurso dos direitos humanos [e da cidadania] sem reconciliação com a memória, sobretudo a daqueles cuja dignidade foi sistemática e institucionalmente aviltada ao ponto de se lhe negar a humanidade", argumenta Schaper ao falar de um país construído às custas do trabalho escravo ${ }^{47} \mathrm{~A}$ violência sistematizada precisa ser deflagrada, exposta, denunciada, não pode ser esquecida.

Pensa-se, portanto, numa pastoral da memória, dialética entre anúncio e denúncia, entre louvor e lamento, por meio do cuidado e contra a violência. A pastoral da

${ }^{47}$ SCHAPER, V. O humano em questão: os direitos humanos como proposta social. In: VIOLA, S.; ALBUQUERQUE, M. (Orgs.). Fundamentos para educação em direitos humanos. São Leopoldo: Sinodal; EST, 2011. p. 72. 
cidadania, expressão que pode sintetizar as contribuições de Gonçalves, Silva, Pauly e Castro, coloca o cuidado em sua dinâmica pública. O cuidado das pessoas mediado também pelo cuidado com o espaço público. Deste modo, a imagem do reino de Deus, desde sua compreensão enquanto reino do shalom, reino da paz, pode ser compreendido também como reino do cuidado. Em intensidade ainda maior do que aquela que organiza uma violência estrutural, a pastoral da cidadania possui como tarefa a gratuidade traduzida em cuidado. Lá onde dói, também devem estar a denúncia da injustiça e o anúncio prático (encarnado) do cuidado. Trata-se, sobretudo, da perspectiva do cuidado como libertação. Assim como o menino cuidava de sua mãe e a mãe cuidava de seu menino, também uma pastoral da cidadania é chamada ao cuidado de quem sofre, seja na atuação pessoal, seja na ação pública por uma sociedade mais justa. Deste modo, pensa-se numa atitude pastoral enquanto superação da atitude violenta. Se, como aponta Castro, a construção do shalom acontece por meio da prática da justiça, agrega-se o cuidado como indispensável para a dinamização salvífica da graça na construção das relações humanas e de um espaço público em que a luta contra as violências seja também programática.

Entretanto, não há aqui a ingenuidade da transformação das estruturas macro por meio do argumento. Os séculos do esclarecimento tiveram em sua companhia políticas violentas de colonialismo, bem como culminaram em duas guerras mundiais, uma guerra fria, além de vários outros conflitos. Neste sentido, corrobora Pauly: "Política não se faz com mera racionalidade, como talvez Lutero tenha se iludido! Política começa com a paixão, e só depois pode estabelecer para si a racionalidade imprescindível" ${ }^{\prime 8}$. A opção que parece viável é aquela da sensibilidade ativada no cotidiano, nos pequenos espaços. No carinho do filho pela mãe, no cuidado da mãe pelo filho, no colocar-se ao lado dos que choram e que fazem memória de seu sofrimento, na atuação engajada nos (pequenos) espaços públicos, consciente do estado putrefato de organizações de poder e, mesmo assim, comovida pela vida que quer mais vida. $\mathrm{Na}$ sensibilidade do mais humano, vivida diariamente, sobretudo, desde impulsos de gratuidade e cuidado. Chamado esse que atinge todas as pessoas de boa vontade - como elabora papa Francisco ${ }^{49} \mathrm{em}$ sua carta sobre o cuidado da casa comum - e que deveria provocar ainda mais aqueles e aquelas que se compreendem diante da dinâmica do seguimento de Jesus de Nazaré e podem ser movidos pessoal e comunitariamente à ética da gratuidade para dentro dessa pastoral do cuidado. Trata-se, portanto, de uma resistência a partir de baixo, na prática da justiça, nos impulsos de gratuidade, na educação para a cidadania, na sensibilização ao mais humano, na construção de novos mundos possíveis nos pequenos espaços de cuidado e gratuidade.

\section{Referências}

BOFF, C. Teologia e prática: Teologia do Político e suas mediações. Petrópolis: Vozes, 1993. BONHOEFFER, D. Letters and Papers from Prison. Editado E. Bethge. London: SCM, 2017.

\footnotetext{
48 PAULY, 1994, p. 169.

49 FRANCISCO. Carta Encíclica Laudato Si': sobre o cuidado da casa comum. São Paulo: Paulinas, 2015. n. 3.
} 
CALDAS, C. Dietrich Bonhoeffer e a teologia pública no Brasil: o conceito bonhoefferiano de 'estar aí para os outros' como pressuposto teórico para a construção de uma teologia pública no Brasil. São Paulo: Garimpo, 2016.

CARRASCOZA, J. No morro. In: ANACOANA, P. (Org.). Eu sou favela. São Paulo: Nós, 2015. p. 9-18.

CASTRO, C. Por uma fé cidadã: a dimensão pública da igreja. Fundamentos para uma pastoral da cidadania. São Paulo: Loyola; São Bernardo do Campo: Universidade Metodista de São Paulo, 2000.

FRANCISCO. Carta Encíclica Laudato Si': sobre o cuidado da casa comum. São Paulo: Paulinas, 2015.

GONÇALVES, A. Pastoral Pública: a possibilidade de uma práxis a partir da Teologia Pública. Protestantismo em Revista, São Leopoldo, v. 27, n. 1, p. 25-35, jan./abr. 2012.

GONÇALVES, A.; SILVA, N. Pastoreio e compaixão: uma contribuição à pastoral urbana a partir da teologia pública. São Paulo: Fonte, 2013.

GRUCHY, J. Public Theology as Christian Witness: exploring the genre. International Journal of Public Theology, v. 1, p. 26-41, 2007.

GRUCHY, S. Of agency, assets and appreciation: seeking some commonalities between theology and development. Journal of Theology for Southern Africa, v. 117, p. 20-39, nov. 2003.

LE BRUYNS, C. O renascimento da teologia do kairos e suas implicações para a teologia pública e a cidadania na África do Sul. In: BUTELLI, F.; LE BRUYNS, C.; SINNER, R. Teologia pública no Brasil e na África do Sul: cidadania, interculturalidade e HIV/AIDS. São Leopoldo: Sinodal; EST, 2014. p. 47-73. (Teologia pública, v. 4).

PAULY, L. Cidadania e pastoral urbana. São Leopoldo: Sinodal, 1994.

RICOEUR, P. A memória do sofrimento. In: RICOEUR, P. A hermenêutica bíblica. São Paulo: Loyola, 2006. p. 239-243.

SCHAPER, V. O humano em questão: os direitos humanos como proposta social. In: VIOLA, S.; ALBUQUERQUE, M. (Orgs.). Fundamentos para educação em direitos humanos. São Leopoldo: Sinodal; EST, 2011. p. 58-76.

SINNER, Rudolf von. The Churches and Democracy in Brazil: Towards a Public Theology Focused on Citizenship. Eugene: Wipf \& Stock, 2012.

SOUZA, J. Subcidadania brasileira: para entender o país além do jeitinho brasileiro. Rio de Janeiro: LeYa, 2018.

SUSIN, L. Conversão ecológica: “conversão da conversão”. In: MURAD, A.; TAVARES, S. (Orgs.). Cuidar da casa comum: chaves de leitura teológicas e pastorais da Laudato Si'. São Paulo: Paulinas, 2016. p. 40-51.

ZEFERINO, J. Karl Barth e teologia pública: contribuições ao discurso teológico público na relação entre clássicos teológicos e res publica no horizonte da teologia da cidadania. 2018. Tese (Doutorado) - PPGT/PUCPR, Curitiba, 2018. 